\title{
Fragmentation of the Media Audience in Kosovo in the Era of the Internet
}

\author{
Alban ZENELI, PhDc \\ Department of Journalism \\ Faculty of Philology \\ The University of Prishtina "Hasan Prishtina", Kosovo \\ E-mail: alban.zeneli@uni-pr.edu
}

\begin{abstract}
Audience fragmentation in the internet era is present also in Kosovo. The few studies of this topic in Kosovo make this article very important as it first studies the Kosovar audience in this form. The research question in this paper is: What kind of fragmentation is most prevalent in the Kosovo audience? Fragmentation of the audience is divided into two types, ranging from access to fragmentation media and access to the user as fragmentation. The research is based on two main methods, survey, and the comparative method. To measure the audience in the case study, a survey was conducted with 1051 Kosovo citizens from seven main regions of Kosovo. This paper finds that audience fragmentation in Kosovo occurs due to several factors. In terms of the type of media, fragmentation is mostly attributed to new types of communication that have a high frequency of use. As for demographic fragmentation, young people are the ones who mostly use new media.
\end{abstract}

Keywords: Audience; Fragmentation; Internet; Kosovo; Media. 


\section{Introduction}

This paper deals with audience fragmentation in the case of Kosovo. The purpose of the paper is to draw a distinction between the approach audiences have to information they receive from different types of media. This distinction can address the fragmentation of the audience into two types, ranging from access to fragmentation media and access to the user as fragmentation.

In theory there are two types of media fragmentation. Media-based fragmentation and user-based fragmentation. According to Webster (2012), media-based audience segmentation is done by first measuring the number of media in which the audience is paying attention, while in the case of the second approach the media user is the one who makes the fragmentation because of his / her choice of medium and content.

The research question in this paper is: What kind of fragmentation is most prevalent in the Kosovo audience? The purpose of this research question is to answer the main purpose of the paper. Audience studies in the case of Kosovo are rare but the use and access to various types of media are high. Therefore, this paper aims to contribute to audience studies in the Kosovo context.

Given that studies in this field in Kosovo are underrepresented in the European academic world, it is also necessary to explain the media ecology in Kosovo. Media pluralism in Europe's newest state began after June 1999 when the United Nations administration began (UNMIK, 1999) its work after the end of this year's war. Since then, radio and television stations that use frequencies to broadcast their programs are required to register with a regulatory body that is the Independent Media Commission (Law on the Independent Media Commission of 2012). This institution, which is a constitutional category, has the obligation to license and regulate this part of the media (Constitution of Kosovo, 2008). With the legal changes of the regulations of this institution, later were added competencies in the registration of cable television systems in Kosovo.

Thus, now the Independent Media Commission has divided licensing into four forms if we look at it from a public perspective: licensing of radio stations, television stations, cable television and cable service providers. From the public data on the IMC web site, the licensing of this institution is done based on the IMC Law (Law on the Independent Media Commission of 2012) and the regulation approved by the IMC Board (IMC-2017 / 2). According to this law and this regulation, the media in Kosovo can be registered as a business or as a property of non-governmental organizations. The licenses issued show that a significant number of local and regional radio and television broadcasters are licensed as non-governmental organizations (IMC, n.d.).

As of August 2018, at IMC there are 83 radio stations and 20 televisions licensed. Of these licensed media outlets, four radio stations have national frequencies (Ra- 
dio Kosova 1, Radio Kosova 2, Radio 21 and Radio Dukagjini), others have regional, local and "low power" frequencies (operating only within a small geographical area (a village, or locality within cities). Of the 83 radios licensed in Kosovo, 53 of them are in the Albanian language, 22 of them were Serbian, 3 were Turkish, two were Bosnian, two were Goran, and one is in Roma language. What is noteworthy about the registration of radio stations in Kosovo is that a large number of minority radio stations are not known unless they are registered as businesses or as NGOs, as the IMC published data do not provide any such explanation.

Data on television broadcasters in Kosovo report that 21 television stations are currently licensed, of which three have national broadcasting frequencies (Radio Television of Kosovo, Television 21 and Kohavision Television), twelve of which have regional broadcasting frequencies and six have local frequencies. Just over a quarter of the IMC licensed frequency broadcasts broadcast in the primary language, a minority language in Kosovo, 5 broadcast in Serbian and one in Turkish, while another 15 broadcasts in Albanian as the main language. From what is seen from the data published by the IMC, only one television is claimed to be owned by an NGO (TV Mitrovica), four televisions including two privately owned national television stations are registered as a Limited Liability Company. What is important to note is that the remaining 15 television stations have not clearly defined their ownership in the public domain owned by the IMC if they belong to private companies or to any non-governmental organizations.

At the Kosovo Business Registration Agency, there are a total of 301 registered businesses registered for web-portals. The Republic of Kosovo has no other agency that is legally required to register online media. Given this fact, the number may be even greater, adding to the fact that some of the online media may not have registered with the agency at all. The online media in Kosovo have no legal obligation to adhere to any code of ethics, however, most mainstream online media are registered with the Press Council of Kosovo, a self-regulatory body formed in 2004 by the then newspaper publishers.

A total of 8 daily newspapers were published in print in 2010 in Kosovo, all of which were members of the Kosovo Press Council (OSCE, 2010). Following the press crisis that has plagued the daily newspapers globally, there has been a shrinking of the number of these newspapers and their circulation in the market in Kosovo. Currently, only half of the newspapers sold ten years ago are sold in the Kosovo market.

This study provides for the first time an audience fragmentation research in the case of Kosovo and may serve as a basis for exploring this area further. This study can also help the media in Kosovo to understand the types of media fragmentation, thus preparing appropriate content for them. 


\section{Theoretical background}

Audience fragmentation is a phenomenon that is constantly studied, especially now that the transformation of different forms of communication is also changing the forms of audience access to the information they need. In a history of thinking about fragmentation and structuring of the auditorium, sociologist Anthony Giddens presents the media as a source of exercising power over the audience. In his studies of social structure, he states that the power exercised through the media influences social action and interaction between structures (Giddens, 1984). "The power within social systems which enjoy some continuity over time and space presumes regularized relations of autonomy and dependence between actors or collectivities in contexts of social interaction. But all forms of dependence offer some resources whereby those who are subordinate can influence the activities of their superiors, this is what I call the dialectic of control in social systems" (Giddens, 1984, 16).

Other scholars have also written about fragmentation as a phenomenon followed by media proliferation. Petti Alasuutari, in "Rethinking for the Audience", cites fragmentation forms for this reason, saying that the audience is no longer directly connected to the stations, but is transformed into an active viewer who is able to choose between different channels. "... as a logical outcome of channel multiplication, audiences tend to fragment. Viewers are no longer stuck with the fixed schedules of established stations as videocassette recorders and specialized cable and satellite channels enable them to multiply the range of their viewing activities. What this means for the television industry is growing uncertainty about audience preferences and the unpredictability of its choices" (Alasuutari, 1999, 112).

However, audience fragmentation studies have taken on a significant leap in developments in the years of studying new forms of communication through media such as online media and social networks. These studies already suggest that fragmentation is also done by smartphones, which have found widespread use. Researchers Karen Rossand and Virigina Nightingale suggest that these changes have changed the media's earlier concept of information and entertainment. "Today, the digitalization, computerization and mobilization of telephony generates almost daily press speculation that the mobile phone is fragmenting the computer -miniaturizing, mobilizing and fragmenting its interactive capacity across a diverse array of new digital media that bind people into the consumerist capitalism of contemporary democracy. Such changes, unfolding now, echo the reverberations felt at the introduction of television, but also challenge the 'information and entertainment' logic that has until recently defined the television industry. Making media more mobile, extending the range of media we engage within the course of doing other things, weaves human bodies into new audience phenomena for which 
we seek precedents from our cultural history. For audiences, the introduction of interactive media has brought with it unprecedented opportunities for engaging more actively with both new and old media" (Rossand \& Nightingale, 2003, 39).

In line with the view that audiences are impacted by technology being fragmented, Philip M. Napoli also speaks saying that traditional audience separation no longer exists. He says the audience is already becoming unpredictable due to the large fragmentation possibilities based on his access to the media. "These technological changes are compelling media industries to think differently about their audiences, undermining traditional conceptual and analytical approaches, while at the same time opening up new dimensions for conceptualizing audiences. Thus, while in some ways audiences are becoming more elusive and more unpredictable, in other ways, new systems of measuring media audiences, of gathering feedback from them, and of anticipating their tastes and preferences, are making it possible for media industries to fundamentally redefine what media audiences mean to them and how they factor into the economics and strategy of their businesses" (Napoli, 2008, 2).

\section{Methodology}

The research is based on two main methods, survey, and the comparative analysis. To measure the audience in the case study, a survey was conducted with 1,051 Kosovo citizens from seven main regions, Prishtina, Mitrovica, Peja, Prizren, Ferizaj, Gjilan and Gjakova. The data requested by respondents at the outset are demographic data intended to divide the audience by region, residence, gender, education, and age. The questionnaire is divided into two main sections, one seeking answers about the types of media and reasons for use, while the other is focused on the time respondents spend using different types of media and their demographic data. The survey was conducted on a total population of 1,739,825 (KAS, 2011) living in Kosovo in which there is significant media pluralism. Out of this population, the sample is composed of 1,051 respondents using multistage sampling, which is representative for total number of 152,785 householders, according to Kosovo Agency of Statistics (KAS, 2011).

In order to test the hypotheses, set out in this paper, it is necessary to compare the different data obtained from empirical research. In this sense, the analysis of comparing data based on different demographic factors and the responses provided by the respondents will be used as a data source, based on the survey conducted for this study.

H1: If the frequency of using online media and social media for information is high, then the fragmentation of the audience is no longer done by traditional media. This hypothesis will be tested by measuring the audience for the types of media they use to keep up with daily events. As a fragmentation type, it is a media centric. The ques- 
tion provides answers to five different options for five-point scaling media types; never, rarely, once a week, once a day, and more than three times a day.

H2: The more new media is used, the more young consumers are avoiding traditional media. The second hypothesis will be tested by combining demographic data that includes respondents' age data by comparing them with time spent in the media.

H3: The male gender is more dependent on the new media than the female gender. Demographic data that includes gender data will also analyze the results compared to the time they spend in the new media to test this hypothesis.

\section{Audience Fragmentation in Kosovo}

The authors, James G. Webster and Thomas B. Ksiazek note two forms of this phenomenon as they talk about audience fragmentation. According to them, fragmentation is done in the first case by the media, which means the kind of media that is "consumed" by the audience. Whereas, the other type of fragmentation according to these traits occurs because of the type of media user, or by their individual taste, based on units such as age, gender and so on (Webster \& Ksiazek, 2012).

These two study-centered approaches have; media as content distributor, in the first case; and the recipient as the recipient and selector of the message in the second case; "Research on media-centric fragmentation uses discrete media outlets (e.g., channels and Web sites) or products (e.g., movies and music) as the unit of analysis" (Webster \& Ksiazek, 2012, 42).

\section{Media-centric}

To see how audiences behave towards different types of media when they need to be informed about daily events, respondents are asked which one they use for this function, television, radio, newspapers, online media or social networks. The results shown in the graph below (Figure 1) provide clarifications as to whether they are ever used, rarely, once a week, once a day or more than three times a day.

The results of the survey show that social networks are the most frequently used with $59.1 \%$ of respondents who stated that they use this type of media more than three times a day for information. Then, portals used by $34.3 \%$ of respondents more than three times a day and television used by $23.4 \%$ of respondents with this frequency. However, television is the media used to inform once a day by $42.2 \%$ of the audience. If we look at it as a whole, the media that are least used by respondents to this survey are the newspapers because $37.9 \%$ of them say they never use it. Then the radio, with $32 \%$ of the audience responding that they don't use this type of media to get information. This result is a clear indication that traditional media has lost the primacy of being used by the audience to be informed, and even online media not long ago considered internet innovation are no longer leading the 


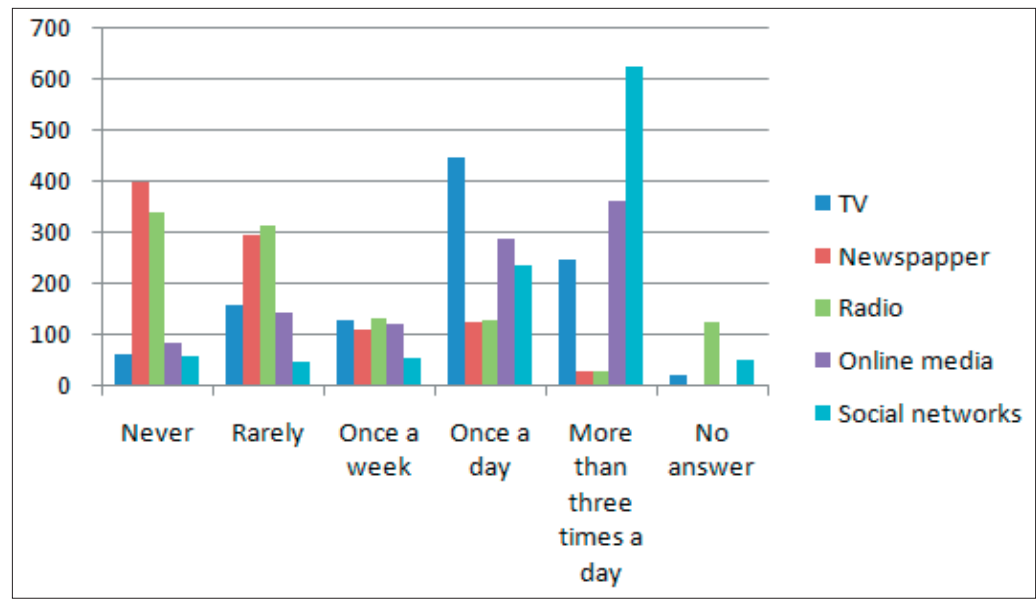

Figure 1. The media used for information

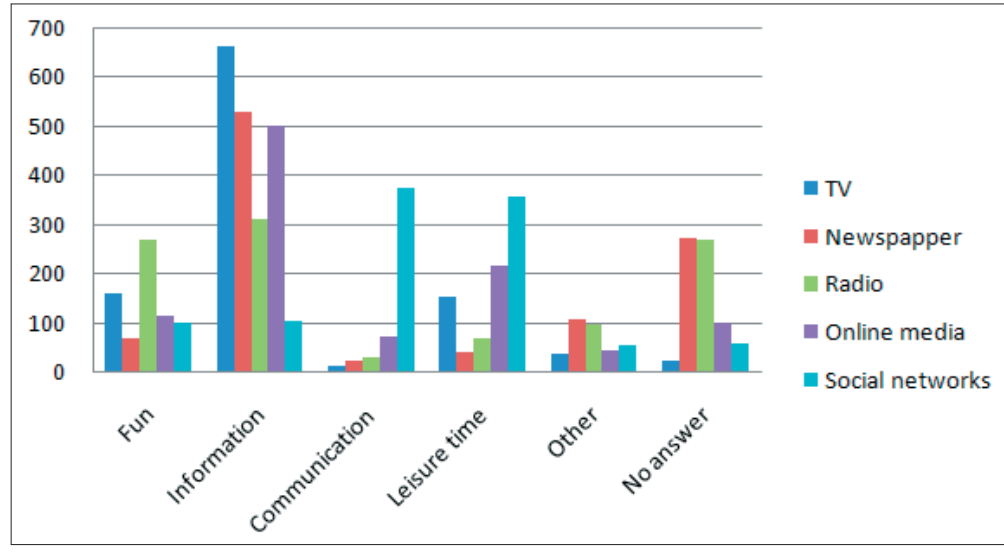

Figure 2. Reasons of media used by audience.

way as research data shows that social networks are those most commonly used by citizens to get information.

Based on the results of the respondents, television is the main media in which citizens are informed, followed by the newspaper with $50 \%$ while online media also constitute an important source of information for respondents and $47.5 \%$ of them use it as a source of information. On the other side, the media are also used for entertainment. Radio with $25.6 \%$ is the most used for this function. Whereas in the response option which type of media they use for leisure time, the survey results show that social networks are most used with $34.1 \%$. Based on these results, it can be said that the new media (online media and social networks) are largely used for leisure time by the respondents. This is in line with the theory of time loss that explains the use of media for leisure time as one of the functions of the media. 
In terms of media use as a function of communication between them, respondents responded that $35 \%$ of them use social networks to communicate.

\section{User-centric fragmentation}

Based on the audience fragmentation study approach that puts the user at the center of the research, below we will present the research results of this case considering characteristics such as age, gender and time spent consuming different types of media. "...each individual's use of media can be widely distributed across providers or highly concentrated on a particular class of products or outlets" (Webster, 2012, 45).

From the results of the research, it could be said that the younger generations from 18 to 35 years are the biggest consumers of new forms of media communication such as online media and social networks. Medoff and Kaye suggested that the web is further fragmenting the audience which has been already fragmented by traditional media (Medoff \& Kaye, 2017, 121).

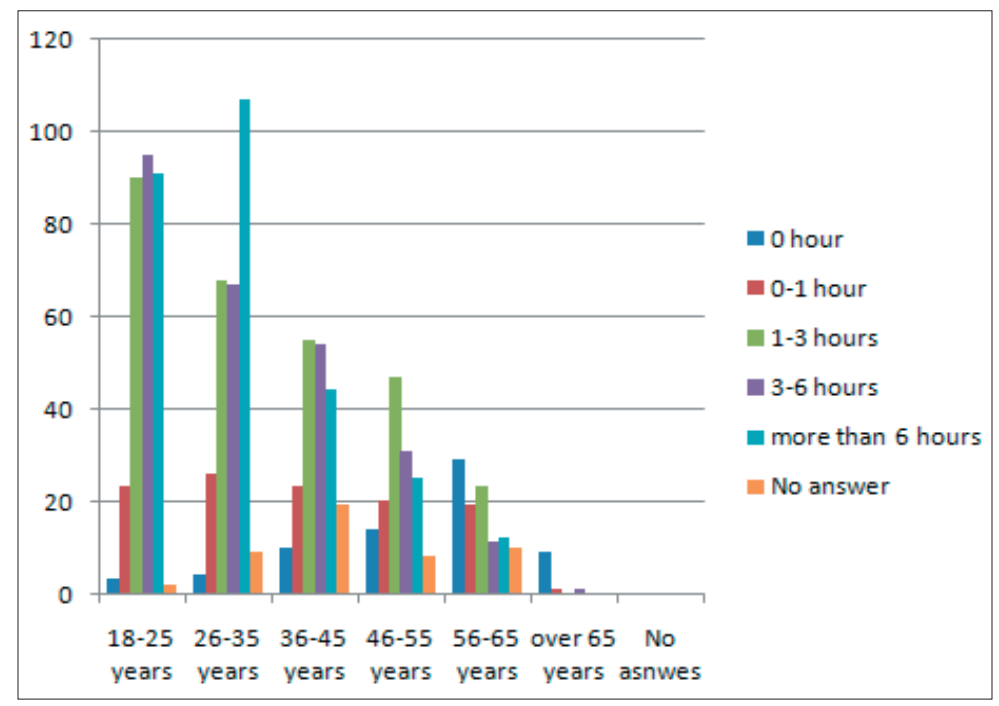

Figure 3. The age of the respondents and the time they spend on social networks

“... Web 2.0 type media have enabled almost anyone to become a producer and distributor of media content" (Macnamara, 2010, 120). These could be one of the reasons why social networks has a high frequency of use. From the data in the table above, it can be seen a large difference in the use of social networks by more than three hours per day by young people. According to the results, $62 \%$ of 18 - to 35 -year-olds use social media at least three hours a day, while $28 \%$ of this age use this type of media more than six hours a day. This indicates a high frequency of use of social networks by young people in Kosovo. 
The use of social networks remains high even when compared to European Union countries. In an EU-made publication, 58\% of Europeans use social media at least once a week. "The use of online social networks is rising, reducing the gap between this medium and the written press: $58 \%$ of Europeans use them at least once a week (+4 percentage points since autumn 2016, +25 since autumn 2010 (EB74)). Over four in ten Europeans do so every day or almost every day $(42 \%,+4$ since autumn 2016)" (EU Barometer, 2017, 4).

Quite the opposite of this is the case of print newspapers. Most of the young people who were part of this survey said that they didn't spend a minute in the newspaper. Survey data shows that $56 \%$ of young people do not use the newspaper at all. But this trend of not using the newspaper for information continues in other ages, ages 36 to 55 have stated that $43 \%$ of them do not spend time reading newspapers.

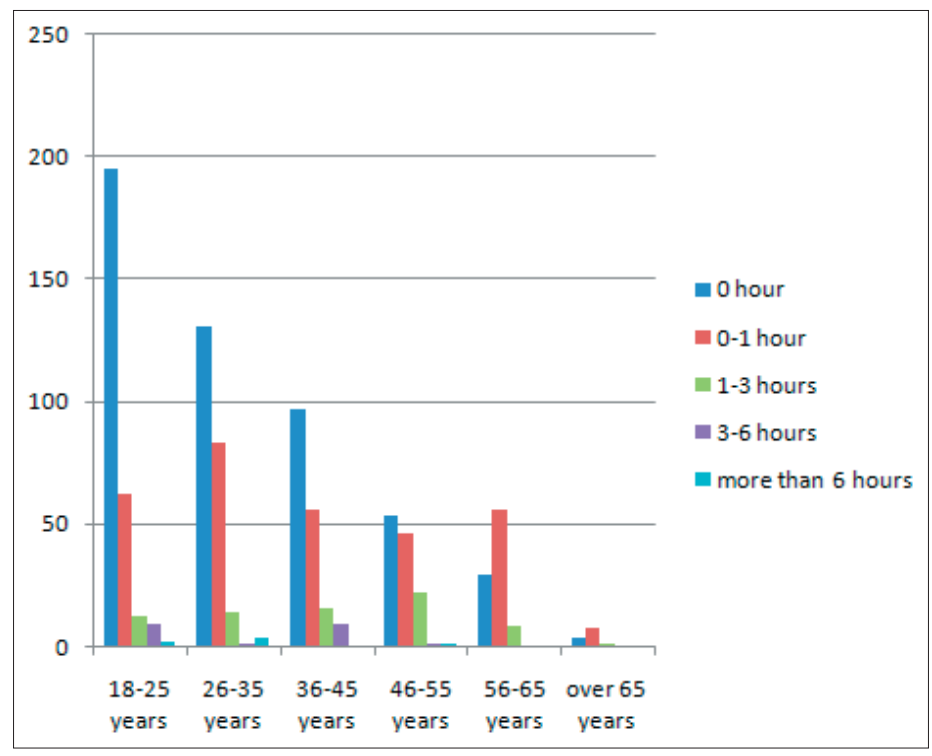

Figure 4. Respondents' time spend on reading newspapers

In the types of media, television still seems to be a compilation of different ages around its screen. This type of medium is consumed by 1 to 3 hours daily, $37 \%$ of respondents of all ages. However, even in the case of television, there is a slight decline in the interest of young people to use it as a means of information. Of the total respondents who do not watch the television for even one hour a day, $75 \%$ of them are aged 18 to 35 years. "These findings provide little support for the notion of a common youth culture, at least as a reflected in the recent television programming. Fragmentation of the television audience extends beyond adolescents" (Potter, 2012, 285). 


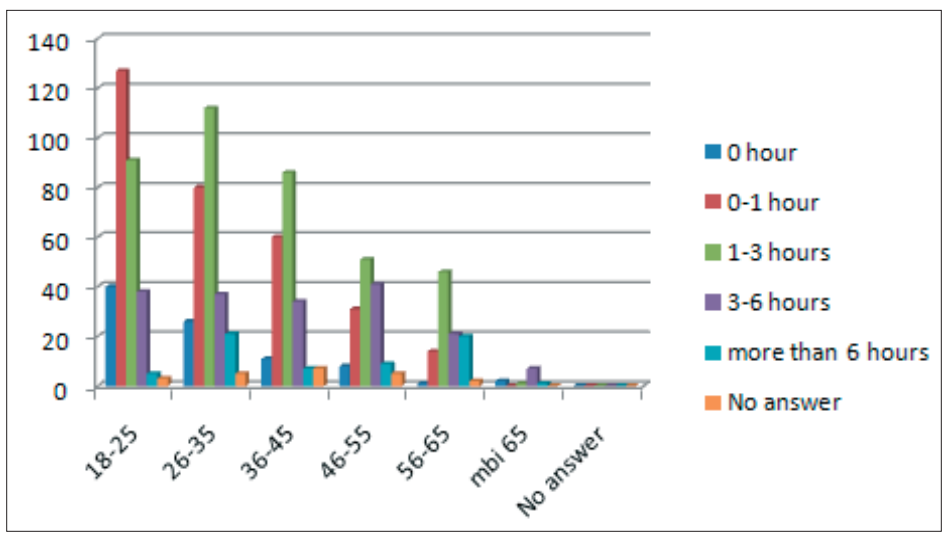

Figure 5. Respondents' age and time spent watching television.

Looking at the gender divide in the case of media users in Kosovo, it can be said that there are not many differences, except that there is a trend of longer media use by men in the more traditional media, while on social networks a longer use by women.

In the case of television, $26.25 \%$ of men spend three or more hours a day compared to women who in $19.88 \%$ of the cases spend the same amount of time in front of the TV.

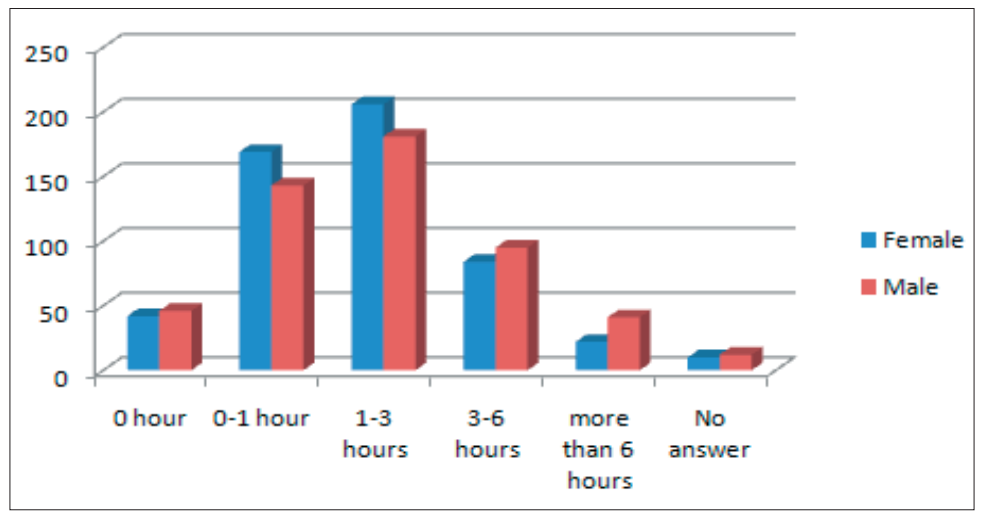

Figure 6. Time spent watching TV on a gender basis.

Things change in the case of social networks, with women expressing a higher tendency to display dependence on social networks. According to the survey results, $28.14 \%$ of women stay longer than six hours on social media, compared to $25.9 \%$ of men who use social media at the same time. Whereas, if the survey is expanded to indicate which gender uses more than three hours a day for social networks, the results of this survey show that more than half of women, or 52.15\% of them, have chosen this option. In a period of three or more hours, in the case 
of men, the score is slightly lower, $50 \%$ of them have indicated that they use it for this time.

The research findings also show that most women use social media more during late evening hours from $9 \mathrm{pm}$ to $12 \mathrm{pm}$. A similar trend of social networking peak times is found among men who use social media in 40 percent of cases.

\section{Conclusion}

Audience fragmentation as a phenomenon that occurs due to media use also applies in the case of Kosovo. Given the fact that there is a huge media plurality for a country of two million people, the fragmentation is sufficient.

From the audience study, in this case, it can be seen that audience fragmentation occurs due to several factors, including the type of media, user demographics. In terms of the type of media, fragmentation is mostly attributed to new types of communication that have a high frequency of use. This is observed with the high usage of social networks. Therefore, it can be concluded that most fragmented are made by dirty social service providers. As for demographic fragmentation, young people are the ones who mostly use new media.

By testing the first hypothesis of this paper, we can say that after testing it has been validated since traditional media are less commonly used by the researched audience. According to the results of empirical research, 59.1\% of the audience use social networks more than three times a day and portals used by $34.3 \%$ of respondents more than three times a day. From these results, it can be concluded that the frequent use of social networks and portals by the audience makes these types of media as one of the main forms of audience fragmentation.

Likewise, the second hypothesis of this paper is confirmed, as young people increasingly avoid using traditional media by replacing them with new media. From the survey results, $56 \%$ of young people between the ages of 18 and 35 no longer use the newspaper for information. Whereas, there is a large number of social media use by this age group as a source of information. According to the survey, $62 \%$ of the respondents use social media for at least three hours a day.

The third hypothesis is tested in terms of gender and the use of social networks is widespread by both genres. However, if addiction can be considered the longer use of some type of media we can say that women are more dependent on social networks, as data show that women use social media for more than three hours in $52 \%$ of cases, compared to men who use $50 \%$ of this time period.

The limitations of this study are the lack of treatment of the content and its types consumed by the audience. Also, this study is limited to scanning the current state of the media as there is no previous study that would provide a comparative basis with other data. 


\section{References}

1. Alasuutari, P. (1999). Rethinking the Media Audience. London: SAGE Publications;

2. Business Registration Agency (n.d.). Retrieved December 2019, from https://arbk.rksgov.net/page.aspx?id=1,42.

3. Constitution of Kosovo. (2008). Retrieved December 2019, from https://gzk.rks-gov.net/ ActDetail.aspx?ActID=3702.

4. European Commission (2017). Standard Eurobarometer, 88, Media use in the European Union.

5. Giddens, A. (1984). The constitution of society: Outline of the theory of structuration. Berkeley, CA: University of California Press.

6. Independent Media Commission (n.d.). Retrieved December 2019, from https://www. kpm-ks.org/te-gjitha-lajmet on 15.12.2019.

7. Independent Media Commission. (2016). Code of Ethics. Retrieved December 2019 from https:/www.kpm-ks.org/assets/cms/uploads/files/Legjislacioni/1476189555.8908.pdf.

8. Kosovo Agency of Statistics (2011). Census Population 2011. Retrieved December 2019, from http://askdata.rks-gov.net/PXWeb/pxweb/sq/askdata/askdata_14\%20Census\%20 population_Census\%202011__2\%20Republic\%20of\%20Kosova/census01.px/table/ tableViewLayout1/?rxid=a9397808-c773-4772-b526-c44c36617e40.

9. Law no. 04/L-044 on the Independent Media Commission. (2012). Retrieved December 2019, from https://www.kpm-ks.org/assets/cms/uploads/files/Legjislacioni/133516 5851.7107.pdf.

10. Macnamara, J. (2010). The 21st Century Media (r)evolution: Emergent Communication Practices. New York: Peter Lang.

11. Medoff, J.N \& Kaye, B. (2017). Electronic Media: Then, Now, and Later. New York: Routledge.

12. Napoli, P. (2008). Toward a Model of Audience Evolution: New Technologies and the Transformation of Media Audiences. McGannon Center Working Paper Series, 15.

13. OSCE (2010). Tirazhi dhe politizimi i mediave të shkruara në Kosovë, Retrieved December 2019, from https:/www.osce.org/sq/kosovo/67791?download=true.

14. Potter, J.W. (2012). Media Effects. Los Angelos: SAGE Publications.

15. Rossand, K. and Nightingale, V. (2003). Media and Audiences New Perspectives. Berkshire: Open University Press.

16. UNMIK. (1999). United Nations Security Council resolution 1244. Retrieved December 2019, from https://unmik.unmissions.org/united-nations-resolution-1244.

17. Webster, J. G. and Ksiazek, Th. (2012). The Dynamics of Audience Fragmentation: Public Attention in an Age of Digital Media. Journal of Communication, 62, 39-56. 